\title{
CARACTERIZAÇÃO DAS FORMAS DE OCORRÊNCIA E ASSOCIAÇÕES DE OURO POR ANÁLISE DE IMAGENS QUANTITATIVA
}

\author{
Fabrizzio Rodrigues Costa ' \\ Guilherme Pinho Nery ' \\ Carina Ulsen ' \\ Daniel Uliana ' \\ Renato Contessotto ' \\ Maria Manuela Maia Lé Tassinari ' \\ Henrique Kahn '
}

\section{Resumo}

As unidades de beneficiamento de minério de ouro buscam cada vez mais uma produção de baixo custo e maximização dos ganhos financeiros. A caracterização tecnológica está inserida em uma abordagem multidisciplinar que permite agregar conhecimento, alternativas de otimização e redução nos custos de operação. Inserida como uma ferramenta na caracterização tecnológica, a análise de imagens automatizada tem relevante papel na mineração devido a agilidade, robustez estatística e confiabilidade nas análises. A técnica pode ser realizada por meio de imagens adquiridas em microscópio eletrônico de varredura, associada a microanálises químicas podendo ser utilizadas em diversas etapas em um empreendimento mineiro. Este estudo tem como objetivo a caraterização tecnológica de minério de ouro utilizando a técnica de análise de imagens automatizada por Mineral Liberation Analyser (MLA). A ferramenta da análise de imagens automatizada mostrou-se bastante eficiente definindo características particulares tais como a identificação das associações minerais, composição mineralógica, partição dos elementos e grau de acessibilidade dos grãos de ouro, o que fornece de forma objetiva subsídios para os trabalhos de planejamento de mina e processamento mineral.

Palavras-chave: Caracterização tecnológica; Análise de imagens; Minério aurífero.

\section{QUANTITATIVE IMAGE ANALYSIS FOR CHARACTERIZATION OF GOLD OCCURENCE AND ASSOCIATION}

\begin{abstract}
Evolution in gold ore processing units are increasingly focused towards efficiency seeking routines, leading to a low-cost and maximal financial gain. The mineral characterization, inserted into a multidisciplinary approach enables a knowledge adding dynamics that results in optimization alternatives and operating cost reduction. Being one of commonly used tools in mineral characterization, automated image analysis plays an important role in the mining sector mainly due to its rapid analysis, statistical robustness and reliability of the results. The technique can be performed using images acquired in a scanning electron microscope, usually associated with chemical microanalysis having applications in different stages of a mining venture. The following study aims to produce a mineral characterization using an automated image analysis technique by MLA. The automated image analysis tool proved to be very efficient defining particular features such as gold association, mineralogical composition, partition of the elements and accessibility of gold grains, which provides an objective subsidy for mine planning work and mineral processing.

Keywords: Technological characterization; Automated image analysis; Gold ore.
\end{abstract}

'Laboratório de Caracterização Tecnológica, Escola Politécnica, Universidade de São Paulo - USP, São Paulo, SP, Brasil. E-mail: fab.costa@usp.br

2176-1523 (c) 2016 Associação Brasileira de Metalurgia, Materiais e Mineração. Publicado pela ABM. Este é um artigo de acesso aberto distribuído sob os termos da licença Creative Commons CC BY-NC-ND (Attribution-NonCommercial-NoDerivs) - https:// creativecommons.org/licenses/by-nc-nd/4.0/. 


\section{INTRODUÇÃO}

A necessidade de explotação de minérios auríferos com teores cada vez menores e com associações mineralógicas mais complexas, tem demandado maior aprofundamento nos estudos de caracterização tecnológica e desafios frente à lavra e processos de beneficiamento [I].

Ao longo da vida útil do empreendimento mineiro, as características do material lavrado mudam conforme as características da jazida e podem comprometer a recuperação metalúrgica das usinas. A fim de minimizar tal efeito, torna-se fundamental o aprofundamento no estudo das características do minério e seu comportamento frente aos processos de concentração e recuperação. Procedimentos acurados e detalhados de caracterização tecnológica são fundamentais para o conhecimento do minério e antever eventuais quedas de recuperação metalúrgica, permitindo propor alternativas de processamento potenciais.

A caracterização tecnológica tem por objeto o estudo das propriedades, físicas, químicas e físico-químicas de matérias primas minerais face ao processo de beneficiamento ou uso final $[2,3]$. Em um aspecto geral, engloba procedimentos em escala laboratorial e desenvolvimento descontínuo, como também estudos aplicados de mineralogia e análises instrumentais modernos.

A análise de imagem foi um campo que se expandiu nas últimas décadas, sendo ferramenta versátil e de grande alcance que permite a obtenção de forma rápida e expressiva de informações como composição mineralógica, partição dos elementos químicos, associações minerais e, principalmente no caso do ouro, a acessibilidade potencial (2D).

\section{I.I Ouro}

O ouro é um bem mineral conhecido e apreciado desde a antiguidade. No Egito antigo, a região do deserto oriental abasteceu o império com cerca de 250 minas com a produção durante várias dinastias egípcias [4]. Possui alta resistência ao ataque químico, alta condutividade elétrica, ductilidade e alta densidade $\left(19,3 \mathrm{~g} / \mathrm{cm}^{3}\right)$. É um metal raro e o seu teor médio na crosta terrestre é de 3 ppb e em jazidas é 10.000 vezes maior, ou seja, pelo menos de 0,3 ppm.

$\mathrm{Na}$ natureza, ocorre predominantemente na forma nativa ou em substituições por outros metais como prata e ainda na composição de outros minerais. $O$ ouro e a prata apresentam grande afinidade formando soluções sólidas em diferentes proporções. A principal delas é denominada electrum, que consiste em uma variedade de ouro nativo contendo $25 \%$ ou mais de prata na sua composição; pode ser encontrado menos frequentemente na forma de teluretos (por ex: $\mathrm{AuTe}_{2}$ : calaverita; $\mathrm{CuAuTe}_{4}$ : kostovita), sulfetos e selenetos (por ex: $\mathrm{Ag}_{3} \mathrm{AuS}_{2}$ : liujinyita; $\mathrm{Ag}_{3} \mathrm{AuS}_{2}$ : fischesserita) [5].

As diversas formas de ocorrência do ouro acabam por direcionar as alternativas de processo para sua extração. Uma classificação feita por premissas quanto à resposta do minério aos processos de beneficiamento e extração hidrometalúrgica é apresentada na Figura I [6,7].

Minérios de ouro "free-milling" são definidos como aqueles onde mais de $90 \%$ do ouro pode ser recuperado por lixiviação via cianetação convencional. Minérios refratários são os que têm baixa recuperação de ouro ou recuperação aceitável com a utilização significativa de reagentes ou processos mais complexos de tratamento (ustulação, etc.) com impacto no custo do beneficiamento.

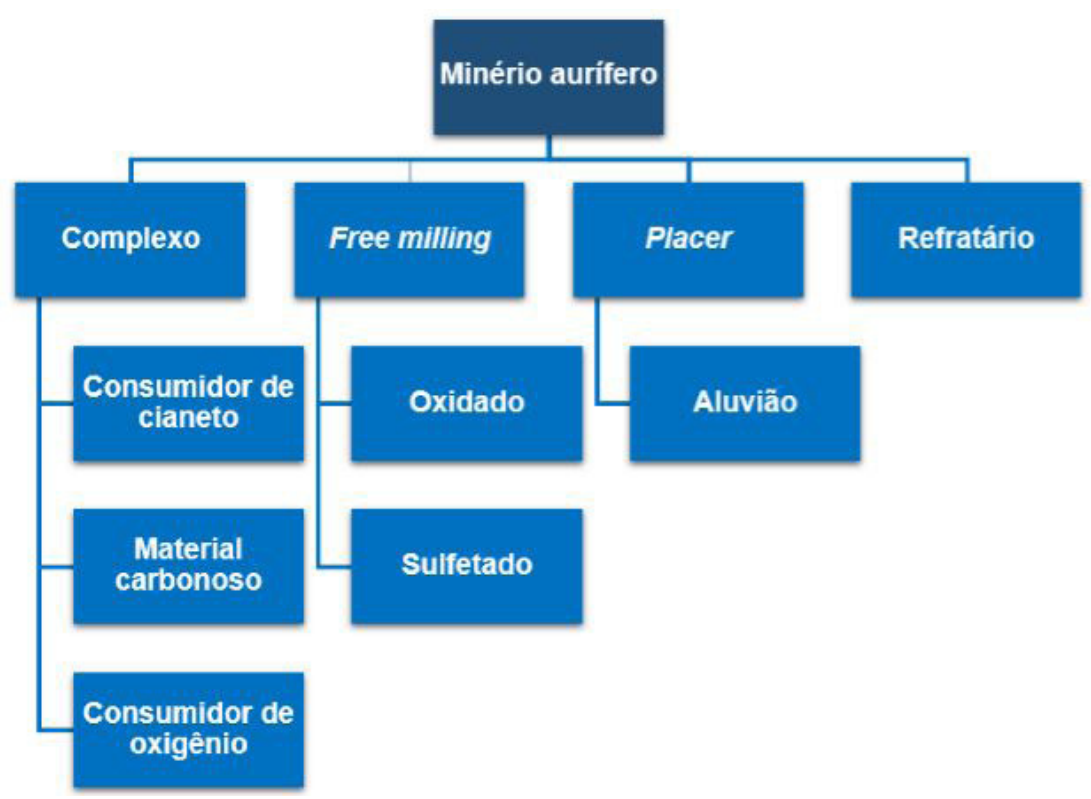

Figura I. Classificação de minérios auríferos quanto ao comportamento na cianetação [6]. 
Os minérios de ouro "free-milling" vêm sendo cada vez mais explotados ao passo que os refratários têm sido mais discutidos na literatura devido a sua complexidade no processo de beneficiamento e à necessidade de desenvolvimento de rotas alternativas no seu processamento $[8,9]$. Os minérios auríferos tipo "pláceres" apresentam grãos de ouro comumente livres por ação do intemperismo, explotados de depósitos aluviares, com concentração mineral feita essencialmente por métodos densitários.

Os minérios complexos ocorrem associados a sulfetos, o que pode afetar a seleção do processo ou as condições operacionais. Esses minérios apresentam alto consumo de cianeto, podendo ocorrer a presença de material carbonoso que adsorve o ouro dissolvido na cianetação, acarretando queda na recuperação.

\section{ANÁLISE DE IMAGENS AUTOMATIZADA E ESTEREOLOGIA}

A análise de imagens tem sido usada na mineralogia aplicada na determinação de informações quantitativas como grau de liberação mineral, distribuição granulométrica de grãos, partículas e suas inclusões, associações minerais, entre outras características relacionadas à sua morfologia [10]. Foi um campo que se expandiu rapidamente devido aos avanços na computação, algoritmos e no aprimoramento das técnicas de microscopia. Em geral, envolve a análise computacional bidimensional de imagens e uma variedade de métodos incluindo estimativa visual, contagem de grãos e medidas de área [II].

O método mais utilizado e de larga aplicação refere-se à análise de imagens adquiridas por microscopia eletrônica de varredura (MEV). A interação do feixe de elétrons com a amostra gera imagens de elétrons retroespalhados (BSE) permitindo a distinção entre as fases presentes pela diferença de número atômico médio, representado em distintos tons de cinza. A identificação das fases pode ser complementada com a determinação da composição química pontual obtida por um sistema de microanálise química através do espectrômetro por dispersão de energia (EDS).

A partir das imagens digitais geradas e processadas por algoritmos, estes sistemas são capazes de compilar em um banco de dados as informações relativas a cada partícula e grão mineral discriminado na análise. A acurácia dos resultados em imagens é garantida pelo princípio da estereologia, que é definida como o estudo de estruturas tridimensionais a partir de imagens bidimensionais [12].

A estereologia é um método que se baseia em seções planares do material (Figura 2) e utiliza amostragem aleatória e sistemática para fornecer dados sem viés [II]. Assim, a acurácia dos resultados obtidos é dependente dos procedimentos de amostragem e preparação de amostras.

Os dois principais e mais antigos sistemas comerciais de análise de imagem automatizada por microscopia eletrônica de varredura são o MLA (Mineral Liberation Analyser) e o QEMSCAN (Quantitative Evaluation of Minerals by Scanning Electron Microscopy), ambos atualmente comercializados pela empresa FEl. Outros sistemas similares foram introduzidos no mercado nos últimos anos, tais como o TIMA (TESCAN), - INCAMineral (Oxford) e o Mineralogic (Zeiss), cada qual com suas particularidades. Esses sistemas possibilitam detalhar as características quantitativas de forma automatizada em curto espaço de tempo, com a coleta de um volume expressivo de informações.

No Brasil, são poucos os sistemas comerciais de análise de imagem automatizada dedicados à caracterização mineralógica. A Escola Politécnica da USP foi uma das primeiras a ter um equipamento instalado, em 2008, com recursos da FINEP. O sistema, instalado no Laboratório de Caracterização Tecnológica do Departamento de Engenharia de Minas e de Petróleo foi também o primeiro em todo o mundo a iniciar as operações conjugadas a um MEV de alta resolução (FEG - field emission gun) com detector de EDS com tecnologia SDD (silicon drift detector) com área de $30 \mathrm{~mm}^{2}$ (Bruker).

\section{I O Sistema MLA - Mineral Liberation Analyzer}

O sistema MLA consiste em um software interligado ao dispositivo de microanálise química (EDS) acoplado ao MEV (Figura 3), que comanda a captura de imagens e a coleta dos espectros de raios $\mathrm{X}$ de um número expressivo de partículas de seções polidas (entre 4.000 e 10.000 ou superior, a depender do número de seções analisadas) [13].

Como o sistema MLA controla o espectrômetro de dispersão de energia, as imagens são coletadas no MEV de modo automático segundo uma rotina previamente estabelecida. A vantagem do MLA de combinar as imagens de elétrons retroespalhados com espectros de raios $X$ característicos das fases (assinatura química) aumenta expressivamente as possibilidades de discriminação dos minerais. A magnificação das imagens (aumento) e a resolução da imagem em pixels definem o tamanho final do pixel nas imagens a serem processadas e são selecionadas pelo usuário em função da textura e associações minerais; de forma semelhante, a aceleração de voltagem $(\mathrm{keV})$ e a resolução dos espectros de raios $X$ podem ser ajustadas para definir o volume de interação dos raios $X$ característicos frente ao tamanho do pixel das imagens. Após a coleta das imagens e espectros de raios $X$, tem-se a etapa de processamento dos dados para discriminação e denominação das fases presentes, determinação de suas proporções em massa (análise modal), morfologia das partículas, associações minerais quantitativas e grau de liberação [13].

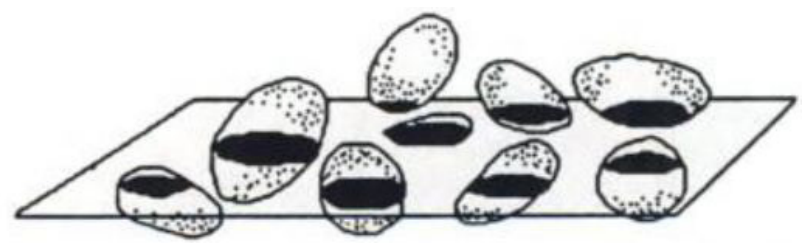

Figura 2. Diagrama esquemático da seção plana [12]. 
Os procedimentos da análise mineralógica quantitativa utilizando o sistema MLA podem ser resumidos nas etapas apresentadas na Figura 4.

A análise de imagens conjugando dados de BSE-EDS permite a identificação e quantificação dos minerais presentes e suas respectivas associações, intercrescimento mineral, com discretização de grãos e inclusões de ouro com dimensões da ordem de até I $\mu \mathrm{m}$. A Figura 5 mostra um exemplo de uma partícula contendo ouro (gold bearing particle), em associações com quartzo e anquerita, com a imagem de elétrons retroespalhados (em tom de cinza) e a classificação dos minerais em falsas cores (amarelo - ouro, verde quartzo, rosa claro - anquerita).

A segmentação das fases é realizada por meio da distinção dos tons de cinza (contraste de número atômico - imagem de BSE) e da composição química (espectros de raios $\mathrm{X}$ ) das feições identificadas; a identificação das fases é obtida mediante comparação de espectros de EDS coletados nos grãos que compõem a amostra e dos EDS oriundos de um banco de dados com espectros coletados para as distintas fases presentes. A Figura 6 apresenta a classificação de partículas de diferentes composições mineralógicas.

Para minérios auríferos, o conceito clássico de grau de liberação descrito por Gaudin [14] perde o seu significado visto que os processos empregados para a sua recuperação e extração se baseiam em propriedades específicas desse elemento, como por exemplo, a formação de amálgamas com mercúrio e sua lixiviação por soluções alcalinas de cianeto. A definição clássica de liberação mostra que em uma população de partículas de diferentes minerais, o grau de liberação de uma das espécies consiste no percentual deste mineral que ocorre como partículas livres em relação ao seu total contido (misto equivalente + livres). Já o grau de associação corresponde ao percentual do mineral que se encontra misto (duas ou mais fases) em relação ao total.

No caso de minério de ouro, o termo acessibilidade é mais adequado pois o grão de ouro não necessita necessariamente estar liberado, mas parcialmente exposto para ser acessado por uma solução lixiviante. A extração do ouro por uma solução de cianeto pode ocorrer através de fraturas ou algum outro meio que propicie $o$ acesso da solução e consequente lixiviação do grão de ouro.

O perímetro exposto de cada partícula na qual o ouro está associado pode ser determinado através da utilização do sistema MLA, o que possibilita o detalhamento das características qualitativas e quantitativas de cada partícula, inclusive sua acessibilidade 2D (valor subdimensionado em relação ao valor real - 3D).

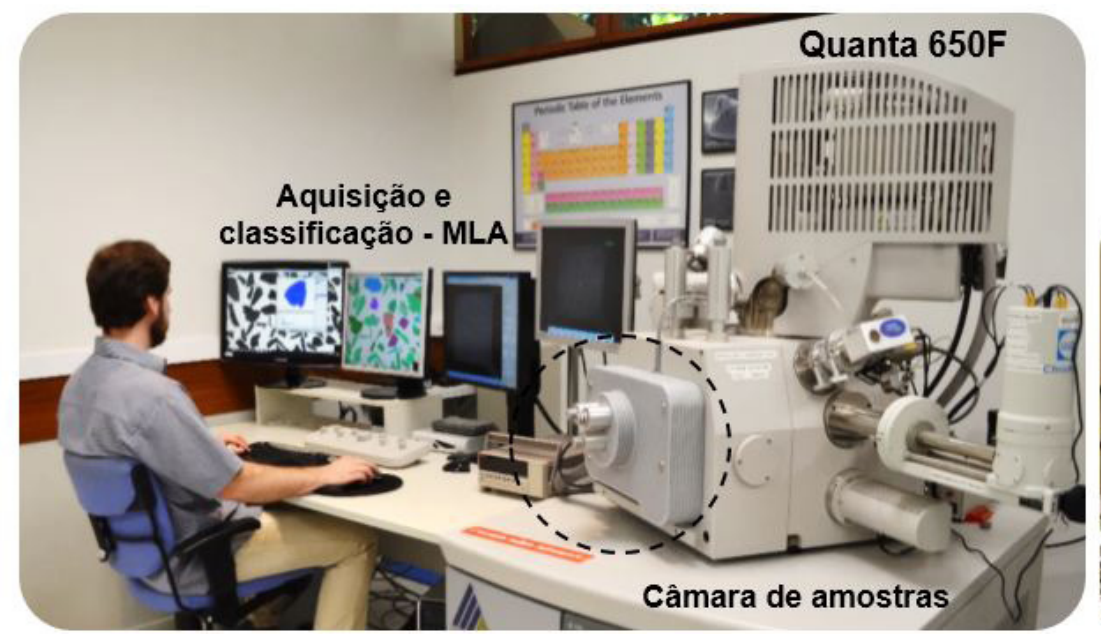

\section{Detalhe da câmara de amostras com as seções polidas}

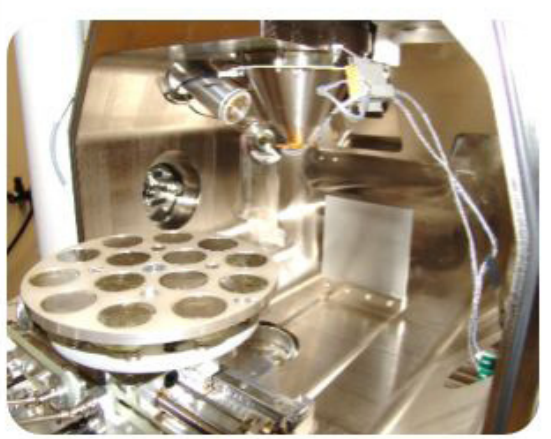

Figura 3. Visão geral do microscópio eletrônico de varredura. Legenda: Microscópio eletrônico de varredura mostrando a aquisiação e classificação por MLA. Detalhe da câmara de amostras com capacidade para I4 seções polidas.

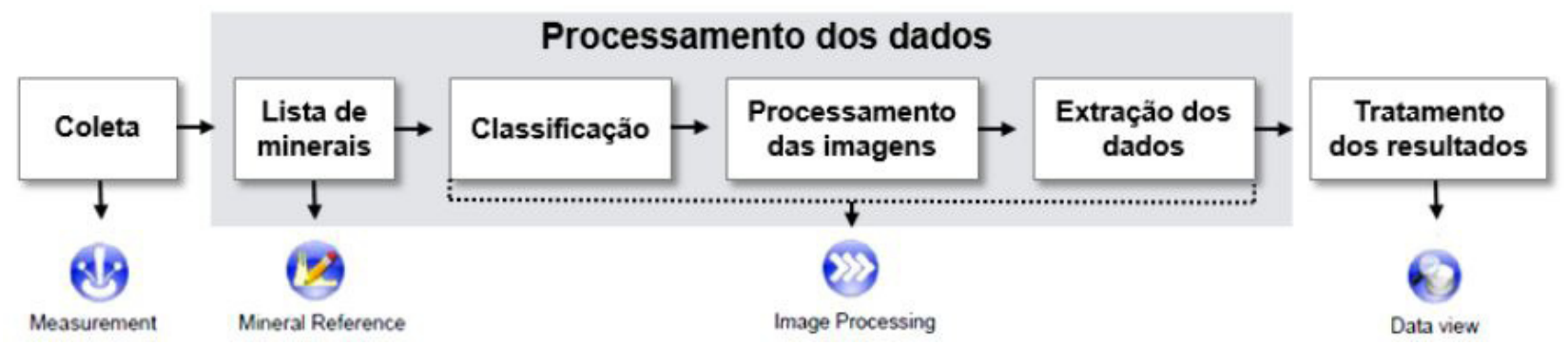

Figura 4. Procedimento de coleta e processamento dos dados. Legenda: Aquisição dos dados até o tratamento dos resultados. Os módulos (measurement, mineral reference, image processing e data view) dizem respeito as rotinas para cada etapa do processo. 


\section{MATERIAIS E MÉTODOS}

Foram selecionadas três amostras, denominadas amostras I, 2 e 3 . As amostras com cerca de $5 \mathrm{~kg}$ foram compostas a partir de um intervalo de I metro de testemunhos de sondagem.

As amostras foram cominuídas abaixo de $0,6 \mathrm{~mm}$, homogeneizado e amostrado para determinação da composição química, mineralógica e estudos de caracterização tecnológica.

Os teores dosados em três alíquotas para cada amostra tal qual variam entre 0,3 e 0,7 ppm.
Uma alíquota resultante $(500 \mathrm{~g})$ da separação da amostra total $(5 \mathrm{~kg})$ foi selecionada para a análise de difração de raios $X$ e analise mineralógica por MLA. Para a análise de difração de raios $X$, as amostras foram cominuídas em moinho de disco e quarteadas até atingir aproximadamente $30 \mathrm{~g}$.

Entre os minerais de maiores proporções identificados, o quartzo e muscovita foram recorrentes nas três amostras estudas. Constituintes minerais em menores proporções tais como feldspato (albita), goethita, clorita (clinocloro), caulinita, sulfetos (arsenopirita, pirita, galena) e três variedades
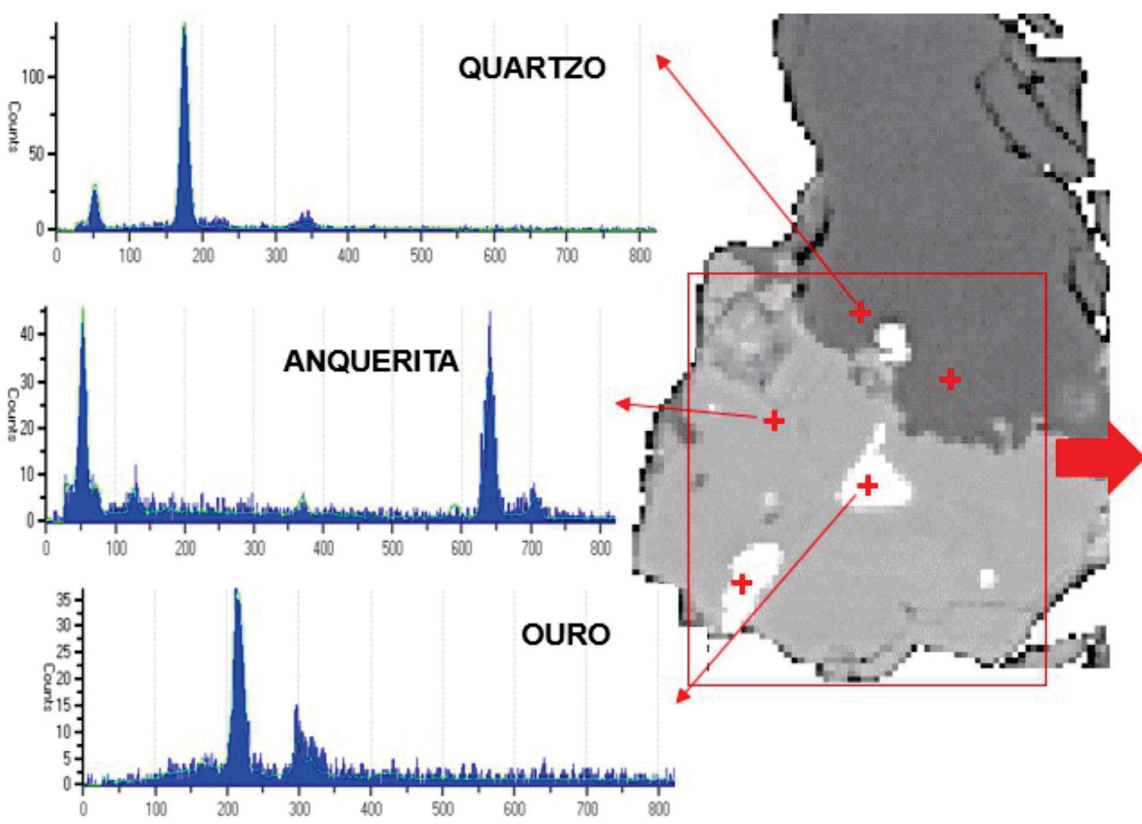

OURO
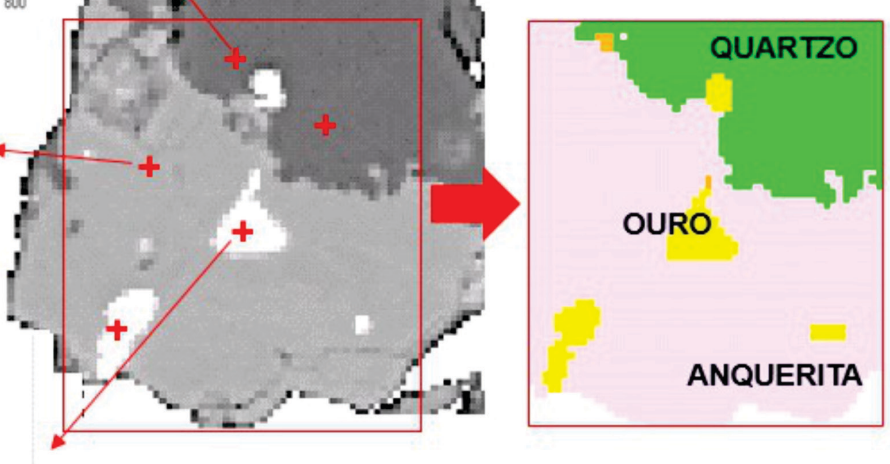

Figura 5. Sistema de classificação automatizada. Legenda: Em amarelo: ouro; verde: quartzo e vermelho claro: anquerita. A foto mostra a imagem de BSE - contraste de número atômico em tons de cinza. Nela é possível observar pelo menos 3 minerais distintos indicados pelos tons de cinza. A imagem em falsa cor indica a segmentação e classificação dos minerais mediante comparação com o banco de padrões de raios $\mathrm{X}$ característicos obtido para os diferentes minerais presentes.

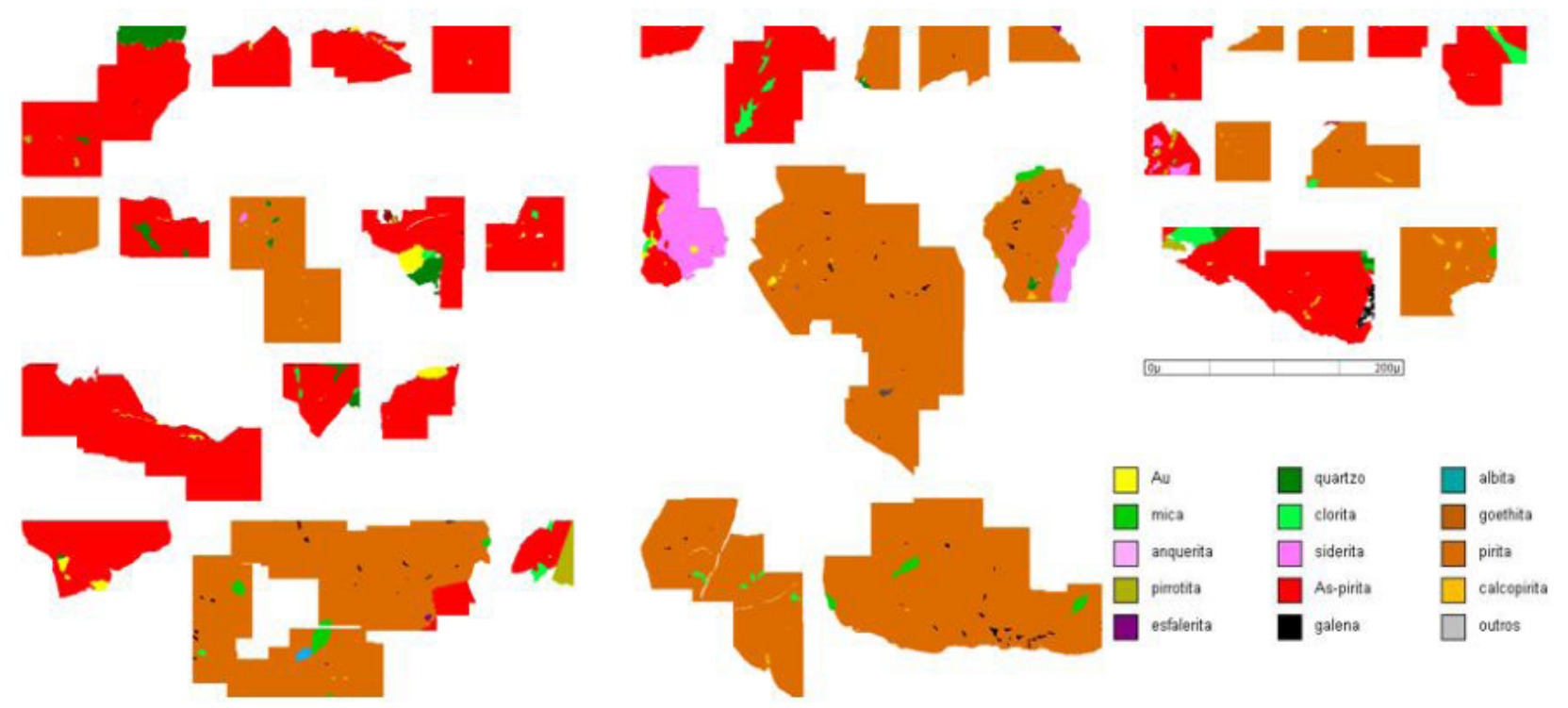

Figura 6. Sistema de classificação automatizada. 


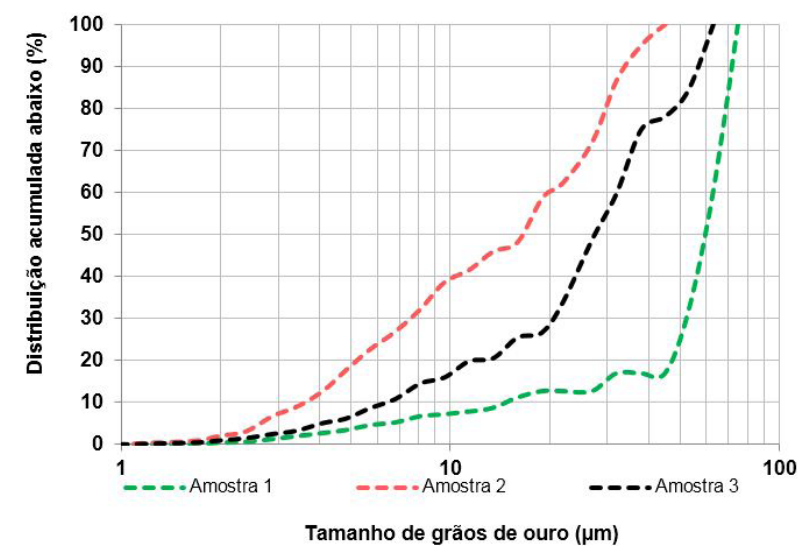

Figura 7. Distribuição acumulada de tamanho dos grãos de ouro por amostra.

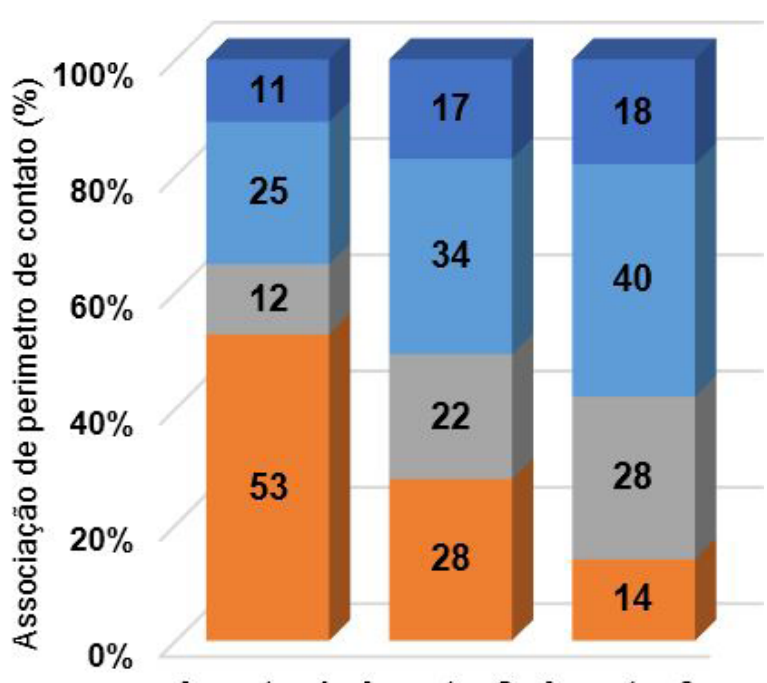

Amostra 1 Amostra 2 Amostra 3

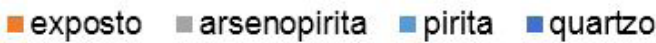

Figura 8. Associação mineral por amostra - grãos de ouro.

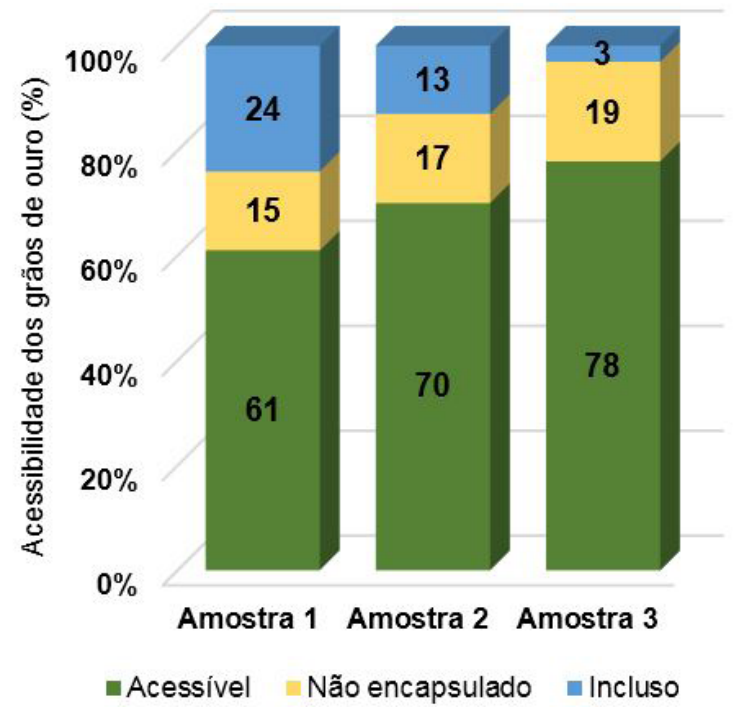

Figura 9. Acessibilidade dos grãos de ouro. de carbonatos: dolomita, anquerita e siderita, ocorrem em proporções variadas nas amostras.

A caracterização das associações minerais foi realizada através de observações sistemáticas ao microscópio eletrônico de varredura (MEV) acoplado a um espectrômetro por dispersão de energia (EDS), para determinação das fases minerais presentes nas amostras e dos minerais associados ao ouro, bem como da composição química pontual destas.

A busca de partículas portadoras de ouro foi efetuada de forma automatizada através do software MLA (Mineral Liberation Analyser - FEI), considerando o número atômico (contraste de níveis de cinza obtidos por elétrons retroespalhados) e composição química (microanálise EDS). Foram determinadas as associações do ouro e seu grau de liberação por perímetro exposto, além da distribuição granulométrica dos grãos de ouro.

\section{RESULTADOS E DISCUSSÕES}

Após classificação das partículas e pós-processamento dos dados, é possível extrair informações como o tamanho de grãos de ouro e das partículas que contêm este elemento, associações minerais em perímetro de contato, grau de liberação do mineral, entre outros. A Figura 7 apresenta a distribuição de tamanhos de grãos de ouro identificados em relação ao diâmetro de círculo equivalente (ECD). As curvas de distribuição acumulada de tamanho de grãos de ouro para diferentes amostras mostram que o sistema MLA possibilita a identificação dos grãos grossos (até cerca de $80 \mu \mathrm{m}$ ) e também dos finos (menor que $5 \mu \mathrm{m}$ ). Observa-se também que amostras diferentes podem apresentar distribuições bastante variáveis, com diâmetro mediano variando de I 5 a $70 \mu \mathrm{m}$.

Na Figura 8 é possível observar com detalhe a associação dos grãos de ouro pelo perímetro de contato (associações minerais relativas ao perímetro dos grãos). $\mathrm{Na}$ amostra I, o ouro está em grande parte exposto na borda das partículas ou em microfraturas abertas (53\%), com $12 \%$ do ouro associado a arsenopirita, $25 \%$ a pirita e I $1 \%$ ao quartzo.

A Figura 9 indica uma tendência de aumento da parcela de ouro acessível 2D (perímetro de ouro exposto identificado em imagens bidimensionais) da amostra I para a amostra 3. A amostra 3 apresenta $78 \%$ dos grãos de ouro acessíveis com 19\% (não encapsulados) e 3\% (inclusos) não sendo passíveis de extração.

A Figura I0A e B mostram diferentes formas de acesso ao grão de ouro. Já a Figura I IA apresenta formas de inclusão e de não encapsulamento (Figura IIB) dos grãos de ouro em imagem bidimensional (2D) onde não seria possível neste plano a ação da solução, pois não há um meio facilitador/condutor para a percolação. 

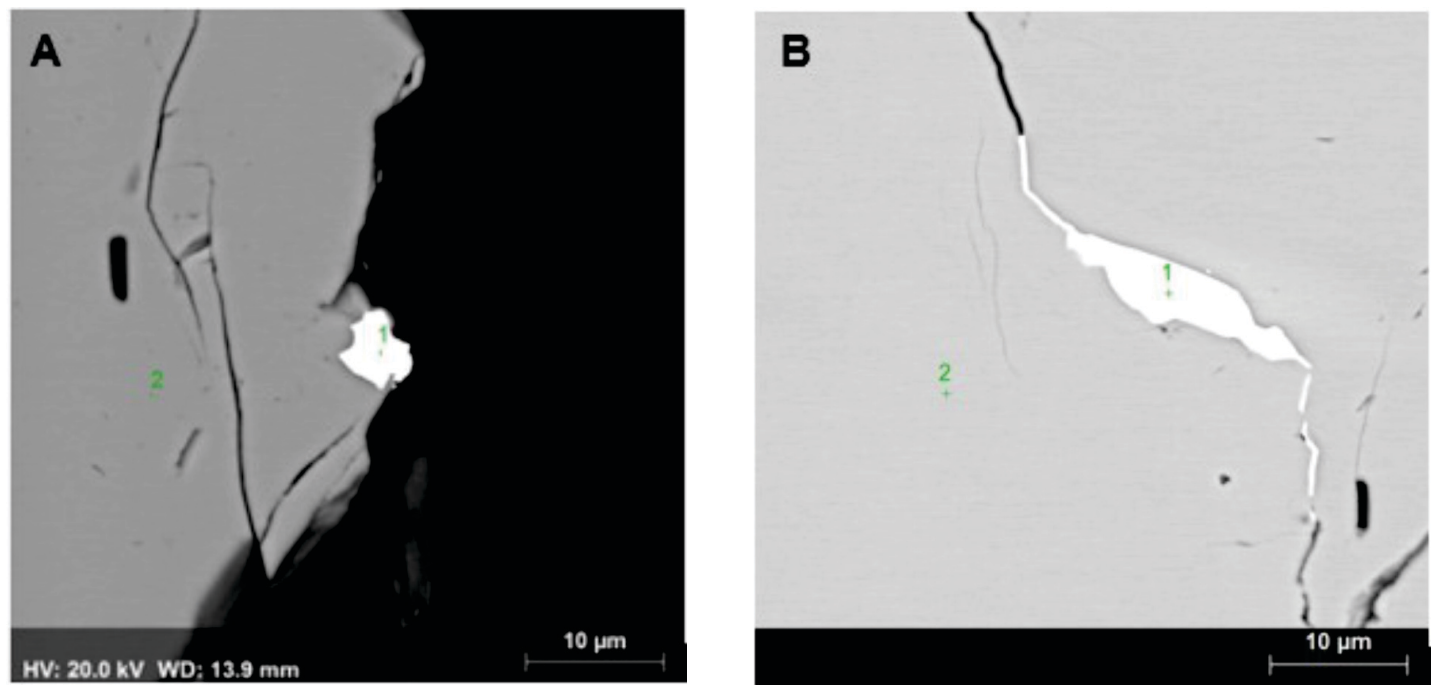

Figura I0. A: llustração sobre a acessibilidade do ouro com perímetro parcialmente exposto e acessível (Au: I; arsenopirita: 2) e B: Grão de ouro acessível por fratura (Au: I; pirita: 2).
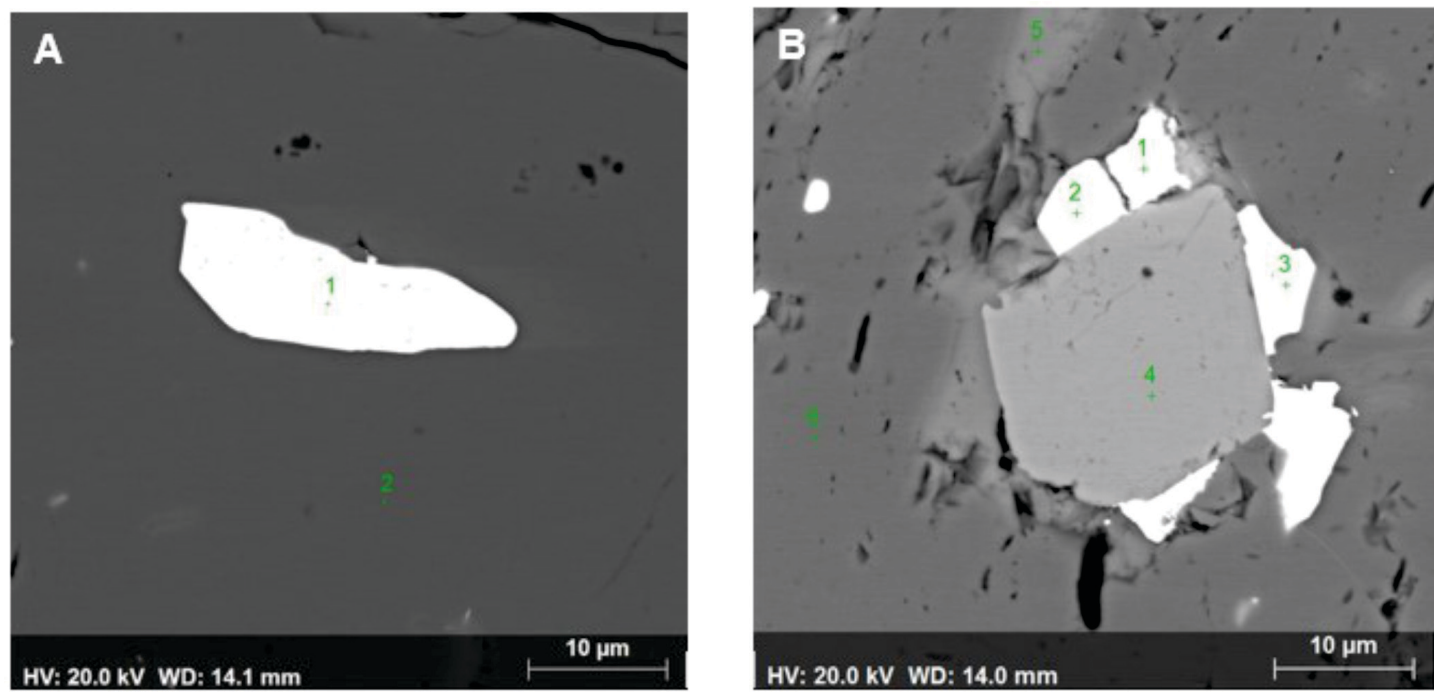

Figura II. A: Ouro (I) potencialmente não extraído, incluso em pirita (2). B: Ouro potencialmente não extraído (I,2 e 3) entre grãos de arsenopirita (4), calcopirita (5) e pirita (6).

\section{CONCLUSÕES}

O sistema de análise automatizada na caracterização de minérios auríferos se expandiu rapidamente nas últimas décadas permitindo a obtenção de quantidades expressivas de informações como composição mineralógica, partição dos elementos químicos, associações minerais, grau de liberação determinados em área ou perímetro exposto e, principalmente no caso do ouro, a acessibilidade potencial (2D). A acessibilidade é um parâmetro importante pois através dela é possível estimar o potencial de extração de ouro por cianetação.

Uma das principais aplicações da técnica de análise de imagens é dar subsídios para a indústria mineral e de materiais na avaliação dos seus produtos ao longo da cadeia de produção. Essa avaliação só é possível por meio de uma análise criteriosa realizada por profissionais especializados em análise e interpretação de uma ampla variedade de materiais e associações mineralógicas possíveis dentro do espectro da geologia, qualificação profissional que exige muitos anos de dedicação e treinamento.

A aplicação de sistemas de análise de imagens automatizada acoplados a microscópios eletrônicos de varredura possibilita a identificação e associações de grãos de ouro em uma ampla faixa granulométrica até poucos micrômetros (I a $2 \mu \mathrm{m}$ ). Tais grãos, antes considerados "invisíveis" pelas técnicas analíticas correntes, por vezes representam mais de $50 \%$ dos grãos presentes em minérios com teores menores que $3 \mathrm{ppm}$.

Portanto, na metodologia exposta foi possível observar que a aplicação da técnica de análise de imagens automatizada corrobora para uma avaliação criteriosa e ágil acerca da associação dos grãos de ouro e grau de acessibilidade de diferentes tipos de minérios. 


\section{REFERÊNCIAS}

I Goodall WR, Scales PJ, Butcher AR. The use of QEMSCAN and diagnostic leaching in the characterisation of visible gold in complex ores. Minerals Engineering. 2005; 18(8):877-886. http://dx.doi.org/10.1016/j.mineng.2005.01.018.

2 Sant'Agostino LM, Kahn H. Metodologia para caracterização tecnológica de matérias primas minerais. São Paulo: Universidade de São Paulo; 1997.

3 Nery G, Ulsen C, Kahn H, Tassinari M, Uliana D. Caracterização de ouro por análise de imagem automatizada por feixe de elétrons. Holos. 20I4;(3):3-10. http://dx.doi.org/I0.15628/holos.20I4.1786.

4 Klemm D, Klemm R, Murr A. Gold of the Pharaohs: 6000 years of gold mining in Egypt and Nubia. Journal of African Earth Sciences. 200I;33(3):643-659.

5 Harris DC. The mineralogy of gold and its relevance to gold recoveries. Mineralium Deposita, Ottawa. 1990;25:S3S7.

6 La Brooy SR, Linge HG, Walker GS. Review of gold extraction from ores. Minerals Engineering. 1994;7(10):12 13|24|.

7 Nardi RP. Análise crítica do desenvolvimento de processos de cianetação em tanques agitados. São Paulo: Universidade de São Paulo; 2000.

8 Henley KJ. A combined mineralogical/metallurgial approach to determining the nature and locating of gold in ores and mill products. Minerals Engineering. 1989;2(4):459-470.

9 Chryssoulis SL, Cabri LJ. Significance of gold mineralogical balances in mineral processing. Transactions of the Institution of Mining and Metallurgy, Section C. 1990;99: Cl-ClO.

10 Petruk W. Applied mineralogy in the mining industry. 2. ed. Ottawa: Elsevier; 2000. 268 p.

I I Henley KJ. Ore dressing mineralogy: a review of techniques, applications and recent developments. Planetary Lecture on Mineral Dressing. 1983;7:175-200.

12 Russ JC. Practical stereology. 3. ed. New York: Plenum Press; 1986.

$13 \mathrm{Gu}$ Y. Automated scanning electron microscope based mineral liberation analysis: an introduction to JKMRC/FEI mineral liberation analyser. Journal of Minerals and Materials Characterization and Engineering. 2003;2(I):33-4I.

14 Gaudin AM. Principles of mineral dressing. 2. ed. New Delhi: Tata McGraw Hill; 1939.

Recebido em: 19 Jul. 2016

Aceito em: 25 Out. 2016 